\title{
Gossypiboma of the Liver: CT, MRI and Intraoperative Ultrasonography Findings
}

\author{
Herwig Cerwenka Heinz Bacher Peter Kornprat Hans-Jörg Mischinger \\ Department of Surgery, Medical University of Graz, Graz, Austria
}

A 57-year-old woman was referred for resection of a tumor with a diameter of $6 \mathrm{~cm}$ located in segment 6 of the liver. Apart from a cholecystectomy 30 years previously she had no history of abdominal surgery. She complained of pain and fullness in the right upper quadrant of the abdomen. Figures $1-4$ show the findings at $\mathrm{CT}$,

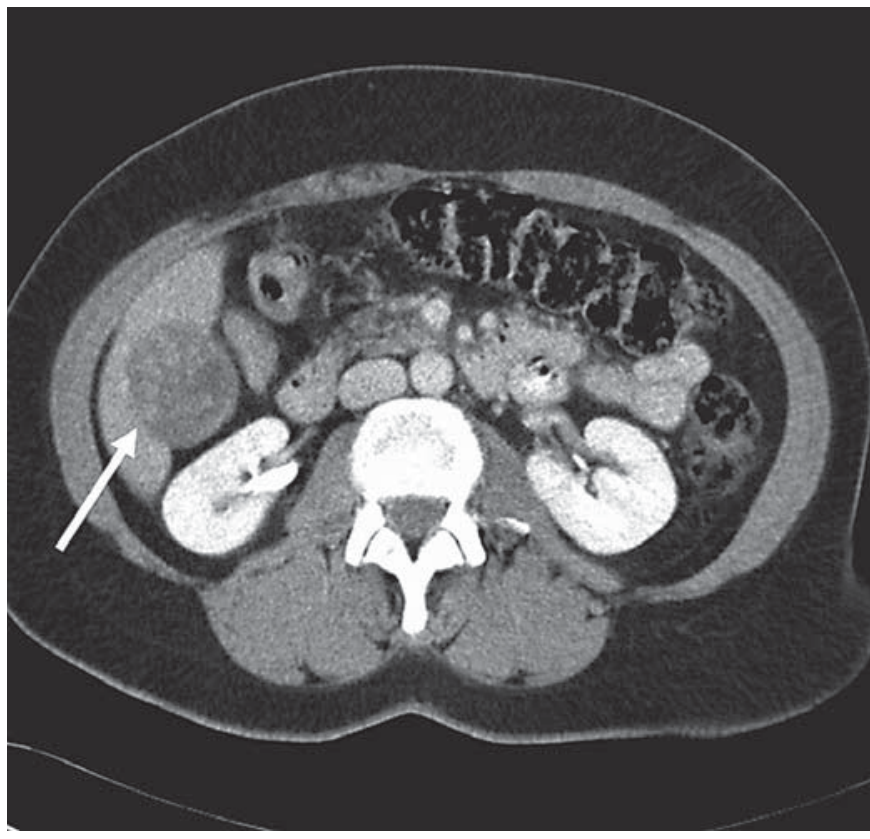

Fig. 1. CT showing a heterogeneous mass of $6 \mathrm{~cm}$ embedded in segment 6 of the liver (arrow).

\section{KARGER}

Fax +41613061234 E-Mail karger@karger.ch www.karger.com
MRI, and intraoperative ultrasonography as well as the operative specimen. Histology yielded cotton remnants and necrotic material with a fibrotic capsule.

Gossypibomas ['gossypium'(Latin) for 'cotton'; 'boma' (Kiswahili) for 'place of concealment'] are masses formed by retained surgical sponges and reactive tissue. Other

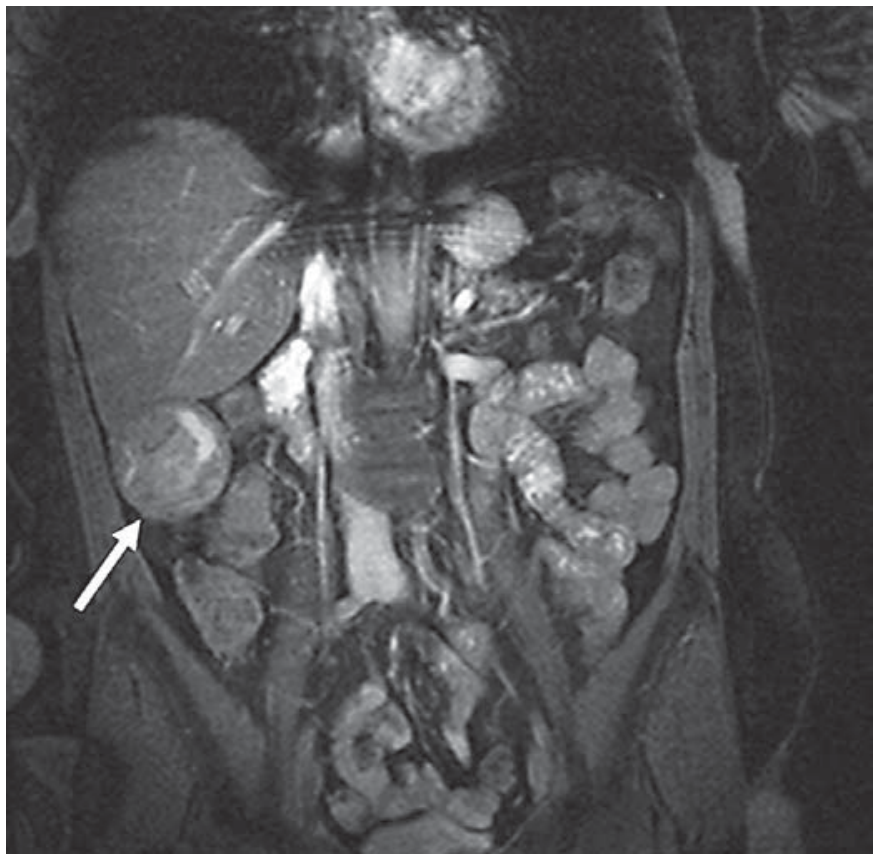

Fig. 2. MRI depicting wavy hypointensities within the tumor (arrow). 


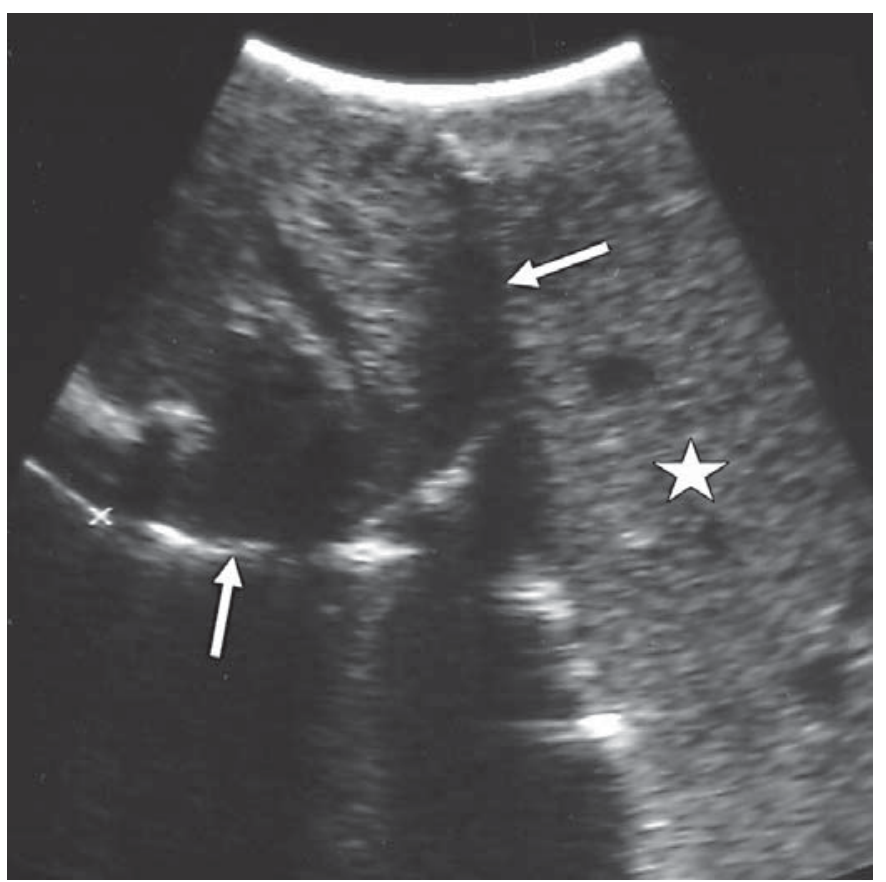

Fig. 3. Intraoperative ultrasonography showing an encapsulated mass (arrows) containing fluid formations and hyperechoic areas. The star indicates the normal liver parenchyma.

terms used for this condition include 'textiloma', 'cottonoid', and 'gauzeoma'. CT-guided core needle biopsy was recently recommended for verification, but our patient opted for surgical removal of the tumor as she was symptomatic. Retained sponges may lead to abscess formation, granulomas, adhesions, chronic inflammation and fistulas or they may migrate into the intestinal lumen, causing perforation or obstruction.

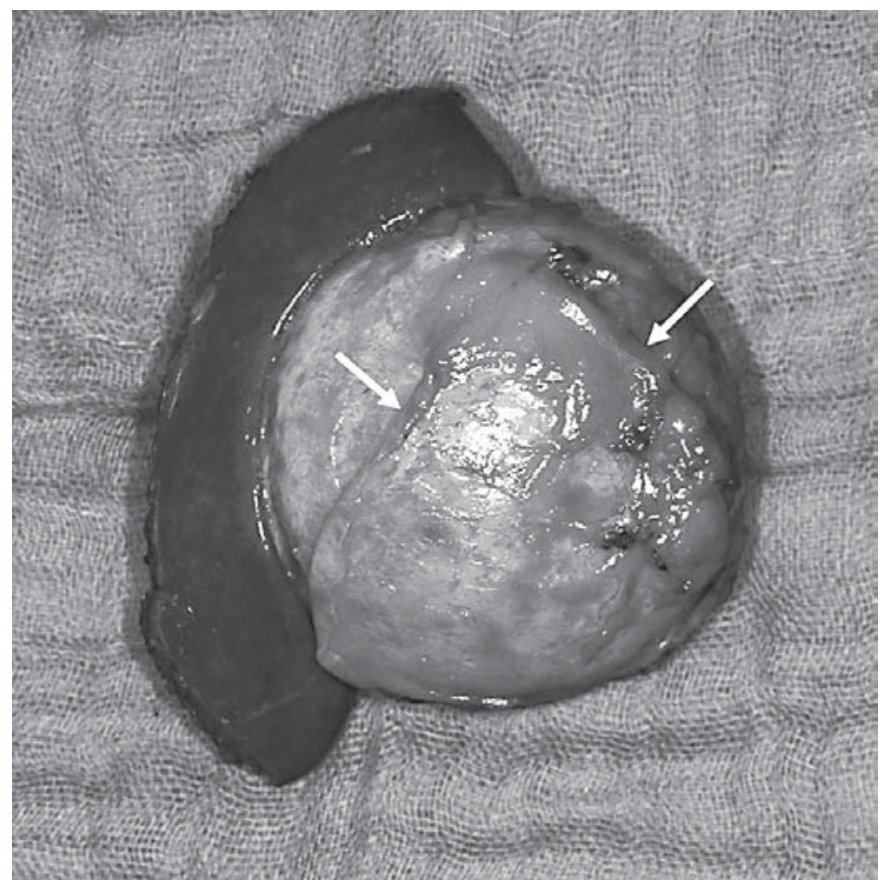

Fig. 4. Surgical specimen. As the tumor adhered closely to the liver parenchyma, it was removed with a margin of normal liver tissue. The slightly irregular surface of the tumor suggests the outlines of the sponge (arrows).

Exact counts of sponges and instruments before abdominal closure are crucial for the prevention of retained foreign bodies. In the case of a gossypiboma, the damage may be limited by diagnosis and removal before serious complications arise. 